Universidad de Guadalajara

Derecho Global. Estudios sobre Derecho y Justicia

Año 4, núm 10, noviembre 2018- febrero 2019, pp- 153-180, ISSN: 2448-5128, e-ISSN: 2448-5136

https://doi.org/10.32870/dgedj.v0i10.199

\title{
El principio de igualdad y no discriminación. Aproximaciones a la discriminación estructural del estado paraguayo hacia los pueblos indígenas
}

\section{The principle of equality and non-discrimination. Approaches to the structural discrimination of the Paraguayan State towards indigenous peoples}

Maximiliano Mendieta Miranda
Universidad Católica "Nuestra Señora de la Asunción", Uruguay maximendieta9@gmail.com

Recibido: 11/04/18 | Aceptado: 07/06/18

RESUMEN: El objetivo de este articulo consiste en aportar delimitaciones a los efectos de avanzar hacia el entendimiento, las causas y consecuencias de la discriminación estructural en el contexto de los pueblos indígenas que habitan la República del Paraguay. La metodología se basa en un estudio y revisión documental con un enfoque cualitativo.

Los pueblos indígenas que habitan la República del Paraguay se encuentran en una situación de vulnerabilidad a causa de una discriminación estructural del Estado paraguayo hacia los mismos. Ésta, se afianza a través de acciones u omisiones por parte de las instituciones del Estado que, observando los hallazgos, generan una importante brecha en relación al acceso a derechos humanos si se compara la población no-indígena con la indígena, encontrándose ésta muy por debajo de aquella. En este contexto, se pueden observar los privilegios que reciben quienes explotan la tierra a través de los agronegocios en detrimento de las cosmovisiones de los pueblos indígenas sobre las mismas.

PALABAS CLAVES: Derechos humanos, pueblos indígenas, tierra ancestral, discriminación racial, discriminación estructural, Paraguay.

ABSTRACT: The aim of this article is to provide delimitations to the concept of structural discrimination in the context of the indigenous peoples that inhabit the Republic of Paraguay. In this sense this material studies the causes and consequences of structural discrimination. The methodology is based on the study and documentary review with a qualitative approach.

The indigenous peoples who live in Paraguay are in a situation of vulnerability due to structural discrimination of the Paraguayan State towards them. This is reinforced through actions or omissions that, observing the findings, generate an important gap in relation to access to human rights if the non-indigenous population is compared with the indigenous population. 
In this context, it can be observed the privileges which received those who exploit the land through agribusiness to the detriment of the indigenous world views on the lands.

KEY WORDS: Human rights, indigenous peoples, ancestral land, racial discrimination, structural discrimination, Paraguay.

\section{SUMARIO}

I. Metodología. II. Introducción. III. Discriminación. IV. Discriminación racial. V. Discriminación estructural. VI. Algunas bases históricas de la Discriminación Estructural desde la tierra. VII. La tierra para la visión del agro-negocio versus la tierra para la cosmovisión indígena. VIII. Limitada infraestructura y recursos humanos del Estado paraguayo. IX. Consecuencias de la discriminación estructural. X. Conclusión. Bibliografía.

\section{Metodología}

El marco metodológico se basa en un estudio teórico que realiza una revisión documental con un enfoque cualitativo. En este sentido, el artículo se centra en una interpretación interdisciplinaria en cuanto al derecho, la política y la infraestructura económica del Paraguay desde los derechos humanos con énfasis en los derechos de los pueblos indígenas.

En ese contexto, el material estudia, por un lado, los índices, estadísticas e información en cuanto a la población indígena en Paraguay, así como las visiones y la infraestructura del Estado paraguayo a través de las instituciones que deben garantizar los derechos humanos de estos pueblos y la no-discriminación. Por otro lado, se toma en cuenta la Constitución de la República del Paraguay (Constitución), en adelante, Constitución, en relación con el Capítulo V "De los pueblos indígenas" y el derecho internacional de los derechos humanos.

Por último, en referencia al método cualitativo es importante agregar que la información recogida se contrasta en la observación que el autor efectúa en las comunidades y pueblos indígenas que visita periódica y permanentemente 
a través del trabajo de litigio e investigación que realiza en Tierraviva, una organización no gubernamental sin fines de lucro que acompaña la reivindicación, la defensa y la recuperación de tierras ancestrales y territorio tradicional en el Chaco paraguayo desde 1994.

\section{Introducción}

Para entender, integralmente, el concepto de discriminación estructural se debe, primeramente, estudiar el contenido del concepto de discriminación tanto en el contexto nacional como en el marco internacional. Es desde este lugar, que se propone avanzar hacia la principal finalidad de este artículo, que es la de seguir construyendo el concepto, la compresión, las causas y las consecuencias de la discriminación estructural hacia los pueblos indígenas en el Paraguay, principalmente, desde el derecho internacional de los derechos humanos, así como desde la realidad indígena en el marco del acceso o negación a los derechos humanos.

Así las cosas, este material se centra en los derechos humanos de pueblos indígenas en el Chaco paraguayo, con énfasis en los territoriales y en la lucha contra la discriminación desde un análisis holístico y estructural, así como dinámico, dialectico, material y espiritual.

Es en este sentido, cuando se habla de discriminación estructural hacia los pueblos indígenas en Paraguay no se puede dejar de estudiar la infraestructura económica y su base ideológica de repetición en relación a los privilegios de los actores del agronegocio ${ }^{1}$, por un lado, y en relación a la exclusión social y pobreza material de los pueblos indígenas, por otro lado.

El material no pretender abarcar la totalidad de un tema complejo y extenso en una publicación, por eso, limita la misma a un enfoque de derechos económicos, sociales, culturales y ambientales (DESCA) centrándose en la

1 El agronegocio, en este artículo, se refiere a actividades relacionadas con la explotación, deforestación, cambio de suelo y/o agricultura maquinizada que tiene por fin, generalmente, el lucro. 
propiedad comunitaria de la tierra, considerando que ésta, en gran medida, es el núcleo central desde donde se desarrolla la cosmovisión indígena y los DESCA ofrecen una mirada más acabada de la situación de exclusión social, pobreza y extrema pobreza material considerando las estadísticas y encuestas que se tienen sobre los pueblos indígenas.

\section{Discriminación}

Delimitar, definir e interpretar el concepto de discriminación es importante teniendo en cuenta el léxico tanto como expresión común definida en el Diccionario de la Real Academia de la Lengua Española así como a nivel de derecho en dos dimensiones: La del derecho internacional de los derechos humanos y la del derecho constitucional, a fin de ir entendiendo y especificando la discriminación racial contra los pueblos indígenas que se estudia en este artículo, a nivel regional y universal, pero haciendo énfasis en el entendimiento nacional. De esta manera, este análisis acercará a comprender y aproximar a la discriminación hacia estos pueblos en su fase estructural que es la que se relaciona, como se verá, con la historia, la infraestructura económica y la mirada del Estado paraguayo hacia los pueblos indígenas.

En ese orden de cosas, en primer lugar, el diccionario antes mencionado, en relación al significado que es de interés, establece que discriminación es "Separar, distinguir, diferenciar una cosa de otra y; Dar trato de inferioridad, diferenciar a una persona o colectividad por motivos raciales, religiosos, políticos, etcétera" (Diccionario de la Real Academia Española). Como se puede observar, si bien a prima facie la segunda parte de la definición es la que debería interesar preponderantemente, no se puede dejar de analizar la primera parte también a fin de que, desde ya, se pueda comprender que los seres humanos y/o grupos de seres humanos son diferentes $\mathrm{y}$, permanentemente, se distinguen en relación a prácticas culturales y cosmovisiones, de ahí la importancia, de proteger esa diferencia cuando es atacada por causas y creencias etnocéntricas, entre otras.

En segundo lugar, cuando se analiza la segunda parte de la definición

\section{6}


otorgada en el párrafo anterior se tiene que ésta se conecta con la lucha jurídica contra la discriminación en el contexto de la negación de derechos a partir de esas diferencias. En ese sentido, tenemos que la Convención Americana de Derechos Humanos (CADHP), en adelante, CAHP, establece la prohibición de la discriminación en sus artículos 1.1 y 24 en virtud del artículo 29 b). En relación al primero de ellos, la misma dice:

Los Estados Partes en esta Convención se comprometen a respetar los derechos y libertades reconocidos en ella y a garantizar su libre y pleno ejercicio a toda persona que esté sujeta a su jurisdicción, sin discriminación alguna por motivos de raza, color, sexo, idioma, religión, opiniones políticas o de cualquier otra índole, origen nacional o social, posición económica, nacimiento o cualquier otra condición social (CADHP, 1976, art. 1.1).

Siguiendo con otros instrumentos internacionales, se tiene que el Pacto Internacional de Derechos Civiles y Políticos de las Naciones Unidas (ICCPR, por su sigla en inglés) establece lo siguiente:

Todas las personas son iguales ante la ley y tienen derecho sin discriminación a igual protección de la ley. A este respecto, la ley prohibirá toda discriminación y garantizará a todas las personas protección igual y efectiva contra cualquier discriminación por motivos de raza, color, sexo, idioma, religión, opiniones políticas o de cualquier índole, origen nacional o social, posición económica, nacimiento o cualquier otra condición social (ICCPR, 1976, Art. 26).

Hasta aquí las cosas, se tiene que la prohibición de la discriminación puede estar contenida en los textos jurídicos de distintas maneras. En el primero de los casos antes citados, se puede observar que actúa como una norma subordinada a los derechos humanos y libertades fundamentales, lo que simplemente enfatiza su carácter holístico en relación a todos y cada uno de estos derechos humanos y libertades fundamentales.

En el segundo de los casos, la prohibición de la discriminación actúa como una norma más autónoma. Sin embargo, que la prohibición de la discriminación sea autónoma o subordinada simplemente es una decisión legislativa que no cambia, en nada, la esencia de la misma teniendo en cuenta que lo fundamental 
es entender que esta prohibición es un Principio y que éste debe transversalizar, todas y cada uno de las declaraciones, convenios, tratados y pactos internacionales de derechos humanos, así como leyes nacionales.

Ahora bien, adentrándose a la legislación nacional a través de la Constitución, la misma señala en su artículo 46, este principio de igualdad y no discriminación estableciendo lo siguiente:

Todos los habitantes de la República son iguales en dignidad y derechos. No se admiten discriminaciones. El Estado removerá los obstáculos e impedirá los factores que las mantengan o las propicien. Las protecciones que se establezcan sobre desigualdades injustas no serán consideradas como factores discriminatorios sino igualitarios (Constitución, Art. 46).

Así las cosas, este principio está contenido en el derecho internacional de los derechos humanos y se denomina principio de igualdad y no discriminación. La Igualdad se refiere a su aspecto positivo y la no discriminación, a su aspecto negativo. La primera, se refiere a perseguir la igualdad en el goce y ejercicio de los derechos humanos y libertades fundamentales y la segunda se refiere a la prohibición de la discriminación cuando la misma limita el acceso a aquellas prerrogativas. Coloquialmente si se quiere, se puede concluir que tanto la igualdad y la no-discriminación son caras de una misma moneda.

A los efectos de entender mejor el aspecto positivo, es decir, el de Igualdad, la última parte del artículo constitucional en cuestión explica lo que se denomina también, en el derecho internacional de los derechos humanos; discriminación positiva, que consiste en las acciones que deben tomar los Estados, a través de políticas públicas, leyes, entre otros, que estén dirigidas a derrumbar y vencer desigualdades en el acceso a los derechos humanos y libertades fundamentales que sufren, principalmente, las personas o grupos de personas que se encuentran en situación de vulnerabilidad a consecuencia de exclusiones que se dan por distintos motivos que pueden consistir, entre otras, a través del sexismo, fundamentalismo religioso, homofobia, xenofobia y/o racismo.

Así también, esta discriminación estructural se arraiga a través de una sociedad, en gran medida, con clara ausencia de cultura que convive con la 
diversidad y conciencia en relación con los derechos humanos y la multiculturalidad paraguaya, que se extiende, desde las autoridades gubernamentales hasta las escuelas y universidades, pasando por los medios comerciales de comunicación y llegando a la gran mayoría de los operadores de justicia.

Volviendo a la discriminación positiva, el capítulo $\mathrm{V}$ de la Constitución establece una regulación diferente en cuanto a las tierras de los pueblos indígenas considerando varios factores como el despojo histórico, la cosmovisión y la usurpación de su territorio: "El Estado les proveerá gratuitamente de estas tierras, las cuales serán inembargables, indivisibles, intransferibles, imprescriptibles, no susceptibles de garantizar obligaciones contractuales ni de ser arrendadas; asimismo, estarán exentas de tributo" (Constitución, Art. 64).

\section{Discriminación racial}

A lo largo de la historia hasta nuestros días, los pueblos indígenas a nivel nacional, regional y mundial han sido víctimas de una violencia, así como de discriminación racial que ha abarcado todo tipo de vejación en contra de sus prácticas culturales que van desde tratos crueles, inhumanos y degradantes, pasando por la explotación, apropiación indebida de sus tierras, llegando a genocidios.

Es por toda esta historia que se empezó a legislar, desde organismos internacionales como Naciones Unidas (ONU), en adelante, ONU, y la Organización de Estados Americanos (OEA), en adelante, OEA, a través de sus mecanismos correspondientes de protección de derechos humanos, declaraciones, tratados y convenios internacionales a los efectos de intentar detener estas violaciones a los derechos humanos y libertades fundamentales de estos pueblos.

Una de ellas, la más específica a nivel universal es la Convención Internacional sobre la Eliminación de todas las Formas de Discriminación Racial (Convención CERD, por sus siglas en inglés) que entró en vigor en 1969 y que cuenta con el Comité para la Eliminación de la Discriminación Racial (Comité 
CERD, por sus siglas en inglés) antes mencionado, que es el órgano de expertos independientes que supervisa la aplicación de la Convención CERD por los Estados partes. Así también, todos los Estados partes tienen la obligación de presentar informes periódicos al Comité CERD sobre cómo se están aplicando los derechos cada dos años. Posteriormente, el Comité CERD examina cada informe y comunica al Estado parte sus preocupaciones y recomendaciones en forma de observaciones finales.

Así las cosas, la Convención CERD establece, en su artículo uno, la definición de discriminación racial:

Distinción, exclusión, restricción o preferencia basada en motivos de raza, color, linaje u origen nacional o étnico que tenga por objeto o por resultado anular o menoscabar el reconocimiento, goce o ejercicio, en condiciones de igualdad, de los derechos humanos y libertades fundamentales en las esferas política, económica, social, cultural o en cualquier otra esfera de la vida pública (Convención CERD, 1969, Art. 1).

De esta manera, se puede decir, que esta definición es la principal cuando se habla de discriminación racial y que dentro de la misma se encuentra, como una de sus formas; la discriminación estructural, la que puede referirse a diferentes grupos discriminados sean indígenas o no, pero que, en este material, se referirá, a la que deben afrontar los pueblos indígenas.

\section{Discriminación estructural}

A los efectos de aproximarse a la definición y alcance de la discriminación estructural contra los pueblos indígenas en Paraguay se debe entender de que ésta, se da de hecho, cuando se observa en la realidad; la profunda desigualdad y brecha, de forma negativa, en el acceso a derechos humanos por parte de las personas integrantes a pueblos indígenas en comparación con la población no indígena:

La población indígena del país evidencia una alta vulnerabilidad en aspectos sanitarios. Asimismo, el tipo de vivienda, mayoritariamente ranchos, responde a la ubicación de la mayor

\section{0}


parte de la población indígena en áreas rurales, y sobre todo al amplio margen de pobreza manifiesto en la falta de servicios básicos: luz eléctrica, agua potable, entre otros, que padecen los pueblos indígenas. En cuanto al acceso de agua potable, sólo el 2,5\% de la población indígena dispone de este beneficio (la gran mayoría solo tiene acceso a tajamar o río) y el $31,2 \%$ posee luz eléctrica. ${ }^{2}$

Así, una vez que se confirma, con datos y estadísticas esta información, se debe establecer y entender las causas que son responsables de estas cifras como las históricas en cuanto a la usurpación de tierras, la corrupción, la infraestructura económica del país, la infraestructura y recursos humanos destinados a garantizar los derechos de los pueblos indígenas, así como la visión del Estado paraguayo en cuanto la cosmovisión indígena, principalmente, a partir de la tierra.

Siguiendo con estas causas de la discriminación estructural también es importante entender, y ya de manera más evidente y negativa en la acción, la falta de infraestructura, presupuesto y recursos humanos de calidad en las instituciones del Estado paraguayo. Así las cosas, si bien no existe una única y consensuada definición de discriminación estructural, este artículo propone una aproximación, en el marco de los pueblos indígenas, la siguiente:

La discriminación estructural son las acciones u omisiones de un Estado que a partir del no reconocimiento o del incumplimiento sistemático de derechos y libertades fundamentales de los pueblos indígenas produce, reproduce o agrava desigualdades históricas y presentes sufridas por éstos, sus poblaciones y personas.

Hasta aquí las cosas, es importante detallar el elemento volitivo en cuanto a que, por ejemplo, en contraposición a la teoría del delito del derecho penal en el contexto del dolo, en la discriminación estructural no es necesario que los Estados tengan la intención de cometer la discriminación, sino que las normas, medidas o prácticas sean discriminatorias en su aplicación, lo que se denomina discriminación indirecta. Ésta, se encuentra referida por la Corte IDH en el caso Nadege Dorzema y otros v. República Dominicana, refiriéndose al "impacto

2 Plan Nacional de Desarrollo http://www.stp.gov.py/pnd/ejes-estrategicos/diagnosticos/grupos-en-situacionde-vulnerabilidad/\#sdfootnote4sym recuperado el 26 de agosto de 2018. 
desproporcionado de normas, acciones, políticas o en otras medidas que, aun cuando sean o parezcan ser neutrales en su formación, o tenga alcance general y no diferenciado, produzcan efectos negativos para ciertos grupos vulnerables" (Nadege Dorzema y otros Vs. República Dominicana, Corte IDH., 2012).

En este contexto, la discriminación estructural se refiere a políticas públicas de las instituciones mayoritarias y al comportamiento de los individuos que aplican estas políticas y controlan estas instituciones, que son racialmente neutrales en su propósito pero que generan un efecto diferencial y/o dañino en los grupos minoritarios. El elemento clave en la discriminación estructural no es la intención sino el efecto de mantener a los grupos minoritarios en una posición subordinada (Pincus, 1994, p. 120).

\section{VI.Algunas bases históricas de la Discriminación Estructural desde la tierra}

Así como cualquier proceso social la discriminación es una situación que se puede reformar con la acción de los seres humanos. Así las cosas, no es un proceso natural sino social e histórico. Y este proceso social e histórico, cuando se habla de la usurpación o apropiación indebida de la tierra ancestral indígena a lo largo de la historia, ofrece información que se relaciona con la discriminación estructural contra los pueblos indígenas, sobre todo si se parte de los privilegios a raíz de la acumulación originaria de las tierras, considerando el presente en cuanto a latifundio, especulación inmobiliaria y agro-negocio, así como violación de derechos humanos. Al respecto, Eduardo Galeano, se remonta a fines del siglo XV, en cuanto a la colonización de Latinoamérica y África para explicar lo siguiente:

El descubrimiento de los yacimientos de oro y plata de América, la cruzada de extermino, esclavización y sepultamiento en las minas de la población aborigen, el comienzo de la conquista y le saqueo de las Indias Orientales, la conversión del continente africano en cazadero de esclavos negros: son todos hechos que señalan los albores de la era de producción capitalista. Estos procesos idílicos representan otros tantos factores fundamentales en el movimiento de la

\section{2}

DERECHO GLOBAL. ESTUDIOS SOBRE DERECHO Y JUSTICIA 
acumulación originaria (Galeano, 1986, p. 46).

Siguiendo en la misma línea, Paola Pelletier explica, que "los datos históricos y sociales explican desigualdades de derecho o, de hecho, como resultado de una situación de exclusión social o de sometimiento de grupos vulnerables por otros, en forma sistemática y debido a complejas prácticas sociales, prejuicios y sistema de creencias." (Pelletier, 2014, p. 207)

Estas complejas prácticas sociales, prejuicios y sistema de creencias, se agregan, se forman y radicalizan en un sistema de valores y principios subsumidos en una Superestructura condicionada por la Infraestructura. En Paraguay, ésta, como se irá observando, descansa en un sistema económico basado en un modelo agro-exportador dominado por el monocultivo de soja y la ganadería, sumado a otros factores que, legales o ilegales, generan una destrucción irracional del ecosistema así como una profunda desigualdad social que converge en un país con un nivel de pobreza, que en el último año, ha aumentado del $26.58 \%$ a $28.86 \%$, lo que significa al menos 1.950 .000 paraguayos empobrecidos, a decir de la Dirección General de Estadísticas, Encuestas y Censos (DGEEC), en adelante, DGEEC. La misma institución oficial del Estado paraguayo establece que en relación con la extrema pobreza, ésta se ha aumentado, en el último año también, de un 5.42\% al 5,73\% (DGEEC, 2017). Por último, se agrega que la pobreza rural - en donde vive la mayor parte de la población indígena - ascendió a 39,72\%, también en el último año (DGEEC, 2017).

Ahora bien, ya más específicamente en el campo de la historia de la discriminación racial en Paraguay y desde el sometimiento de los pueblos indígenas por parte del Estado paraguayo y/o de empresas y personas, debemos decir que estos pueblos, han sido discriminados y excluidos, social y estructuralmente, a través de la colonización, la neo-colonización y desde ahí a través de la invasión, el despojo y la expoliación de la tierra, recurso natural fundamental para estos pueblos en relación con sus prácticas culturales y cosmovisión.

De esta manera, es justamente la tierra, desde donde este análisis se centra teniendo en cuenta que ésta constituye, a decir de la Corte IDH, el eje sobre el cual gira la satisfacción de otros derechos humanos cuando hablamos de los pueblos 
indígenas no sólo por significar su medio de subsistencia, sino porque constituye un elemento fundamental de su cosmovisión, religiosidad, cabe sostener, de su identidad cultural (Yakye Axa Vs. Paraguay, Corte IDH. 2005).

Así las cosas, y antes de retroceder en el tiempo, es fundamental decir, en el contexto legislativo, que la reforma constitucional de 1992 introdujo la discriminación positiva en un capítulo específico que reconoce los derechos de los pueblos indígenas en Paraguay. Éste obedece, entre otros aspectos, a la larga historia de explotación, asimilación forzada y expulsión de sus propias tierras y territorio, circunstancia que empieza, con la colonización que explicaba Galeano a principios del siglo XVI, lo que significó, el mayor genocidio ocurrido en la historia de la humanidad, resultado víctimas los pueblos indígenas que habitaban las Américas, aunque no se pueda precisar con exactitud la cantidad específica de muertes y atentados contra la etnicidad, las prácticas culturales, las formas de vida y la cosmovisión de estos pueblos.

Considerando la limitación en la extensión de este artículo, se citará en el contexto de las tierras y el territorio indígena, cuatro momentos claves en la historia desde la independencia política de 1811 hasta la situación contemporánea, en cuanto a la expoliación y despojo de este derecho ancestral que abarcará muy resumidamente, desde el gobierno de Don Carlos Antonio López, pasando por las consecuencias de la Guerra de la Triple Alianza y la dictadura del general Alfredo Stroessner a través del partido político denominado Asociación Nacional Republicana (ANR), en adelante, ANR, hasta el presente en cuanto a modelo agroexportador, base de la infraestructura económica del Paraguay como ya se manifestaba anteriormente.

En primer lugar, el 7 de octubre 1848, a través de un decreto dictado por el entonces Presidente del Paraguay, Carlos Antonio López, se decidió sustraer todo el patrimonio y las tierras comunales de los 21 Pueblos Indígenas establecidos en la región oriental en la época colonial previa, declarando a sus miembros como "ciudadanos."

3 ABC Digital, 30 de abril de 2006, http://www.abc.com.py/edicion-impresa/suplementos/cultural/decreto-decarlos-antonio-lopez-del-7-x-1848-901174.html recuperado el 22 de julio de 2018. 
Así, esta decisión no solo vulneraba la cultura, las lenguas y las tradiciones de los Pueblos Indígenas, sino que se encaminaba a asimilarlos a la sociedad paraguaya, a los efectos de crear una sola nación formada por paraguayos y paraguayas, pero sin tener demasiadas consecuencias en la realidad cuando hablamos de la apropiación material de las tierras considerando que no existía un avance importante sobre el territorio indígena para explotarlo o incluirlo al desarrollo nacional.

Esta decisión dejó, al menos en términos legales y sociales, por una parte, a gran parte de la población indígena sin sus tierras ancestrales y, por otro lado, al Estado en espera de la transformación de los y las indígenas a la sociedad paraguaya blanca (Zanardini, 2010 p. 34-35), circunstancia que no se pudo concretar debido a convicción de los y las indígenas en cuanto a mantener su cosmovisión y prácticas culturales, las que se dinamizan con el correr del tiempo, a través de un proceso de resistencia y resiliencia.

El segundo momento, se remonta a los años comprendidos entre 1883 y 1885, luego de la guerra de la triple alianza contra el Paraguay, en el que el presidente de ese entonces, Bernardino Caballero, vendió grandes extensiones de tierras con pueblos indígenas enteros viviendo en ellas, prácticas estatales que siguieron ocurriendo, sistemáticamente, hasta nuestros días, como lo fue, por ejemplo, la venta de las tierras de la comunidad indígena Cuyabia del pueblo Ayoreo, con las familias viviendo adentro, por parte del Lic. Rubén Darío Quesnel, presidente del Instituto Paraguayo del Indígena (INDI), en adelante, INDI, en el 2012, quien fue condenado por la justicia penal a seis años y cuatro meses de pena privativa de libertad.

Así, luego de la decisión de Bernardino Caballero, se conformaron extensos latifundios que darían un paso decidido en la formación del neoliberalismo en la historia paraguaya inclusive antes que, en otros países de la región. De esta forma, se empezó a concretar el proceso de privatización y concentración de tierras, quizás más significativo de la historia desde las independencias políticas de Sudamérica en cuanto a concentración de tierra en manos de capitalistas extranjeros, grandes establecimientos ganaderos y de empresas extractivistas. 
Esta situación no solo despojó a los y las indígenas de sus tierras, sino que apuntó a una profundización de una asimilación forzada, así como la afirmación de la esclavitud laboral de las y los indígenas en sus propias tierras a mano de los nuevos capitalistas que hasta hoy practican formas contemporáneas de esclavitud como lo ha establecido Urmila Bhoola, relatora de Naciones Unidas, en su última visita a Paraguay, en el 2017. En ese marco, la misma establece que:

Los pueblos indígenas que viven en la región del Chaco se ven obligados a trabajar en condiciones de explotación profunda. La región del Chaco representa el $60 \%$ del territorio paraguayo, pero sólo el 3\% de la población, ya que muchas familias han sido desplazadas históricamente como resultado de la pérdida de tierras o han emigrado a áreas urbanas para buscar oportunidades económicas. Parte de este movimiento se atribuyó a la pérdida de empleo y tierras causadas por la privatización a gran escala de la tierra. Es un área principalmente rural, habitada tradicionalmente por diferentes grupos indígenas Nivacle, Enlhet Norte, Enxet Sur, Angaite, Sanapana, Ayoreo, Guayaní Ñandeva. Los pueblos indígenas de la región del Chaco son a menudo objeto de extrema pobreza, exclusión social y discriminación. ${ }^{4}$

\section{La relatora agrega que}

Muchos pueblos indígenas permanecieron en la región del Chaco y se convirtieron en una fuente de mano de obra para los terratenientes. Su vulnerabilidad a las prácticas laborales profundamente explotadoras se ve agravada por la ausencia del Estado en la región, la falta de conciencia de sus derechos, la incapacidad de hablar español en algunos casos y los altos niveles de analfabetismo (Bhoola, 2017).

Continuando con el despojo territorial histórico, es fundamental acotar lo que la Corte IDH manifestó en la sentencia de la comunidad indígena Xákmok Kásek del pueblo Sanapaná contra el Estado paraguayo en la que este tribunal supranacional manifiesta lo siguiente:

A finales del siglo XIX, el Estado vendió dos tercios del Chaco para financiar la deuda del

4 Declaración de fin de misión de Urmila Bhoola, Relatora Especial sobre formas contemporáneas de esclavitud, incluyendo sus causas y consecuencias, ¿al concluir su visita al Paraguay del 17 al 24 de julio del 2017 https:// www.ohchr.org/SP/NewsEvents/Pages/DisplayNews.aspx?NewsID=21903\&LangID=S recuperada el 26 de agosto de 2018. 
Paraguay tras la llamada guerra de la Triple Alianza, con desconocimiento de la población indígena que allí habitaba. Desde entonces las tierras del Chaco paraguayo han sido transferidas a propietarios privados y fraccionadas progresivamente en estancias, obligando a muchas de las aldeas indígenas de los alrededores a concentrarse en las mismas (Kákmok Kásek Vs. Paraguay, Corte IDH, 2010).

Por otro lado, entrando a un tercer momento ya en la historia moderna, durante los 35 años de la dictadura militar de la ANR comandada por Alfredo Stroessner, desde 1954 hasta 1989, se profundizó ese proceso que había comenzado luego de la guerra de la Triple Alianza y que se viene fortaleciendo hasta nuestros días con la liberalización del comercio en relación con la promoción, expansión y protección del sistema agroexportador basado en la actividad agrícola, forestal, ganadera y de monocultivo de soja conectados con la concentración de la tierra y la tenencia latifundista predominante.

De hecho, durante el estronismo, en un marco de corrupción, prebendarismo y tráfico de influencias se entregaron millones de hectáreas a amigos del dictador, correligionarios y militares. En ese marco, explica José Galeano, que "desde el año 1954 al 2003, se distribuyeron 7.851.295 hectáreas a 1.000 personas, lo que representa el 20 por ciento del total territorio paraguayo en manos del 0,00015 por ciento de los y las paraguayas" (Galeano, 2014, p. 30).

En cuarto y último lugar, ya desde 1989, año en que es derrocado Stroessner y en que comienza la transición democrática, se consolida esta infraestructura económica que venimos repitiendo por la importancia que adquiere y que se basa en los agronegocios; principalmente el monocultivo de soja y la ganadería, con políticas públicas que favorecen la radicalización de los latifundios, situación que también convierte al Paraguay en el país más desigual del mundo en relación a la distribución de la tierra, como lo demuestra el indicador Gini. Así, explica Galeano, que "entre 1991 y 2008, la concentración de la tierra se agudizó: el indicador Gini de desigualdad de la tierra, que se mide de o (igualdad perfecta) a 1 (desigualdad perfecta), se incrementó de 0,91 a 0,03 , siendo así el más elevado del mundo" (Galeano, 2014, p. 30).

Así como se ha observado, durante estos cuatro importantes momentos 
históricos se vulneraron y violaron derechos territoriales indígenas a través de la expoliación, la apropiación indebida y la expulsión de sus propias tierras lo que ha generado en estos pueblos una exclusión social y pobreza material. A estas condiciones se le suma, como se analizará más exhaustivamente en el próximo apartado, una mirada sesgada hacia la cosmovisión territorial indígena cuando esta colisiona con la visión comercial mercantilista y capitalista del agro-negocio lo que genera estigmas, prejuicios y discriminación, social y estructural, contra los pueblos indígenas.

\section{La tierra para la visión del agro-negocio versus la tierra para la cosmovisión indígena}

Por un lado, según el DRAE, visión, entre otras acepciones similares, significa "contemplación inmediata y directa sin percepción sensible (DRAE). Por otro lado, según el mismo diccionario, cosmovisión se refiere a la "visión o concepción global del universo" (DRAE).

Se hace la anterior diferenciación para entender que la primera de ellas podría estar más asociada a la concepción de la tierra por parte del agro-negocio considerando que ésta se limita a una mirada mercantilizadora de la tierra en la que la misma, a través de actividades como la explotación, deforestación, cambio de suelo y/o agricultura maquinizada, tiene por fin, generalmente, el lucro, a secas.

Sin embargo, cuando se habla de la tierra en la concepción de los pueblos indígenas se tiene que la misma trasciende una visión meramente material, explotadora y de lucro, y se conecta con la vida y la forma de ver, entender y sentir el mundo desde la misma. Esto es así ya que, en gran medida, la relación indígena con la tierra trasciende un bien material para convertirse también en bien espiritual que se relaciona con una visión, principalmente, no explotadora ni mercantilista de la tierra sino más bien, en conexión con sus antepasados, así 
como prácticas ancestrales como la caza, recolección, producción de artesanía y vida colectiva en sus tierras, todo esto, limitado a raíz consecuencias que genera el agronegocio así como la desidia y discriminación estatal.

Para entender mejor esta premisa, la Corte IDH, en el caso Sawhoyamaxa Vs. Paraguay del 2016, establece un paradigma en esta diferencia que se señala de la siguiente manera:

La garantía del derecho a la propiedad comunitaria de los pueblos indígenas debe tomar en cuenta que la tierra está estrechamente relacionada con sus tradiciones y expresiones orales, sus costumbres y lenguas, sus artes y rituales, sus conocimientos y usos relacionados con la naturaleza, sus artes culinarias, el derecho consuetudinario, su vestimenta, filosofía y valores. En función de su entorno, su integración con la naturaleza y su historia, los miembros de las comunidades indígenas transmiten de generación en generación este patrimonio cultural inmaterial, que es recreado constantemente. (Sawhohayamaxa Vs. Paraguay, Corte IDH., 2016).

Esta afirmación realizada por el tribunal supranacional en la sentencia antes mencionada, la realizó, justamente, debido a la convicción que sostenía el Estado paraguayo en relación a las tierras cuando defendió criterios inconstitucionales y violatorios del derecho internacional de los derechos humanos anteponiendo al derecho humano a la propiedad indígena de la tierra, el derecho a la propiedad privada a través del argumento principal de que esas tierras estaban racionalmente explotadas. La misma posición la defendió en los casos de la comunidad Yakye Axa y en el de la comunidad Xákmok Kásek, ambas anteriormente mencionadas.

Al respecto, la Corte IDH fue clara al señalar que los Estados deben valorar caso por caso las restricciones que resultarían del reconocimiento de un derecho por sobre el otro, debiendo tener en cuenta que al desconocerse el derecho de los miembros de las comunidades indígenas sobre sus territorios ancestrales, se podría estar afectando otros derechos, dado que los derechos territoriales indígenas abarcan un concepto más amplio y diferente que está relacionado con el derecho colectivo a la supervivencia como pueblo organizado, con el control de su hábitat como una condición necesaria para la reproducción de su cultura, 
para su propio desarrollo y para llevar a cabo sus planes de vida (Sawhoyamaxa Vs. Paraguay, 2016).

Como se puede observar de las sentencias de la Corte IDH antes mencionadas, la visión y posición del Estado paraguayo privilegia intereses latifundistas y ganaderos sobre derechos humanos de pueblos indígenas, situación que limita el derecho y acceso a la tierra indígena y que, de esta manera, arraiga la discriminación estructural.

La dicotomía entre las dos visiones de la tierra es también detallada por Victoria Tauli-Corpuz, relatora especial de Naciones Unidas sobre derechos de pueblos indígenas que visitó el Paraguay estableció que:

Dada la especial relación y dependencia de los pueblos indígenas respecto a sus tierras, territorios y recursos naturales, los pueblos indígenas están entre los más afectados por las formas de producción insostenibles y la destrucción ambiental. Además de la pérdida de los bosques y otros ecosistemas y de los conocimientos tradicionales y sistemas económicos asociados, la Relatora Especial recibió también información sobre los impactos de la utilización de pesticidas, especialmente en las grandes plantaciones sojeras, que están afectando los derechos a la salud y otros derechos de los pueblos indígenas. ${ }^{5}$

La posición del Estado paraguayo no es única en la región ya que se extiende a otros países que cuentan con el mismo modelo meramente mercantilista de las tierras. En ese contexto, un principio cultural del neoliberalismo, explica Rodrigo Navarrete, es que, si bien el régimen productivo y la economía globalizada puede gestionar las demandas indígenas por seguridad en la tenencia y acceso a tierras, esto ocurre siempre y cuando "éstas entren de alguna forma al juego de la economía global o no representen un conflicto con intereses económicos de otros sectores más dinámicos e integrados" (Navarrete, 2010, p. 8).

Continuando con las violaciones a los derechos territoriales indígenas a través de posiciones discriminatorias por parte del Estado paraguayo, en el caso Xákmok Kásek, la Corte IDH declaró responsable internacionalmente a

5 Tauli-Corpuz, Victoria (2015). Informe. Situación de los pueblos indígenas en el Paraguay.

Informe. $\quad \mathrm{http} / /$ unsr.vtaulicorpuz.org/site/index.php/es/documentos/country-reports/84-report-paraguay Recuperado el 27 de agosto de 2018. 
aquel por la falta de garantía del derecho de propiedad comunitaria, las garantías judiciales, la protección judicial, así como por la violación a los derechos a la vida, integridad personal, reconocimiento de la personalidad jurídica, los derechos del niño y por el incumplimiento del deber de no discriminar (Xákmok Kásek Vs. Paraguay, 2010).

Así, entre otros estándares internacionales contemplados por la Corte IDH, en esta sentencia, la Corte IDH enseña, como se viene afirmando, como el privilegio a los intereses de la infraestructura económica asentada en el agronegocio vulnera los derechos humanos de los pueblos indígenas al establecer que el Estado paraguayo discrimina en "la prevalencia de una visión de la propiedad que otorga mayor protección a los propietarios privados por sobre los reclamos territoriales indígenas, desconociéndose, con ello, su identidad cultural y amenazando su subsistencia física" (Xákmok Kásek Vs. Paraguay, 2010).

\section{En ese mismo marco, la Tauli-Corpuz explica que}

La privatización general de las tierras y la falta de un registro catastral adecuado han generado una superposición de títulos de propiedad, que originan reclamaciones múltiples sobre determinadas áreas; estas reclamaciones suelen fallarse en favor de las empresas, despojando de la tierra a los pueblos indígenas. Según fuentes oficiales, el proceso de expropiación que debería aplicarse para la adjudicación de tierras indígenas es, en muchos casos, irrealizable por el alto precio de la tierra y termina favoreciendo a los propietarios privados. Esto hace que el proceso de titulación se limite a extensiones de tierras discontinuas, lotificadas y, muchas veces, insuficientes (Tauli- Corupz, 2016).

Continuando con la discriminación estructural contra los pueblos indígenas basada en los privilegios de los actores del agronegocio y la visión del Estado paraguayo, la relatora especial manifestó que:

Los problemas socioeconómicos que afectan a los pueblos indígenas no puede disociarse del contexto socioeconómico general del Paraguay. Como señaló la relatora especial sobre la extrema pobreza y los derechos humanos, existen en el país una serie de factores estructurales como la corrupción, la enorme desigualdad, un sistema tributario regresivo, la excesiva concentración de la tierra y la degradación ambiental que, junto con la debilidad institucional, obstaculizan los avances en la lucha contra la pobreza. El modelo de desarrollo del país, que 
fomenta un rápido crecimiento económico a través de actividades como los monocultivos, en particular la masiva extensión del cultivo de la soja, o la ganadería, ha tenido como resultado la mayor tasa de deforestación en el mundo, aumentando los problemas ambientales causados por los cultivos transgénicos y con grandes insumos de productos químicos (Tauliz-Corpuz, 2016).

\section{Limitada infraestructura y recursos humanos del Estado paraguayo}

El principio de igualdad y no-discriminación, así como se ha observado, no solo se encuentra legislado en el derecho internacional de los derechos humanos sino en la Constitución, específicamente, en su artículo 46. Éste, es claro al establecer que el Estado paraguayo debe priorizar e impulsar acciones y políticas públicas que apunten a garantizar que, grupos excluidos y discriminados, como los pueblos indígenas, accedan, en realidad, a todos los derechos humanos considerando la profunda brecha que existe, en este contexto, entre la población indígena y no indígena.

Sin embargo, el Estado paraguayo, está lejos de destinar el presupuesto adecuado, de consolidar una infraestructura y recursos humanos suficientes y de calidad, y de estructurar un sistema de justicia, que garantice el respeto, la promoción y la vigencia de los derechos humanos de los pueblos indígenas, lo que constituye una discriminación estructural, de hecho, hasta podríamos agregar, intencionadamente. Esta discriminación se acrecienta con la visión asistencialista y paternalista, sin enfoque de derecho, que tiene el Estado paraguayo para con los Pueblos Indígenas.

En ese sentido, el Comité CERD ha manifestado en relación con Paraguay, lo siguiente

Preocupa al Comité, la discriminación estructural de la cual continúan siendo víctimas los pueblos indígenas, así como la discriminación e invisibilidad que enfrentan los afroparaguayos, lo cual se pone de manifiesto en la brecha de desigualdad en el ejercicio de los derechos 
humanos de los pueblos indígenas y afroparaguayos, en relación al resto de la población (arts. 1, 2 y 5) (Comité CERD, 2016).

Ahora bien, centrándose en la débil infraestructura del Estado paraguayo a los efectos de garantizar los derechos humanos de los Pueblos Indígenas, se debe empezar por citar al INDI cuya misión es "garantizar el cumplimiento de los derechos indígenas de modo articulado y coordinado con otras instituciones, armonizando los mandatos legales del Estado con la participación de los pueblos indígenas." 6

Sin embargo, en la realidad, el INDI es una institución que no cuenta ni con un presupuesto suficiente ni con infraestructura ni recursos humanos que puedan garantizar, mínimamente, los objetivos de la institución y más si se habla, de presupuesto para la compra de tierras, una acción que ha sido una máxima durante el gobierno de Horacio Cartes (2013-2018).

El INDI, se encuentra en un edificio precario y minúsculo en el centro de la ciudad de Asunción, capital del Paraguay, con recursos humanos que no solo son, radicalmente insuficientes, sino que cuenta con una gran mayoría de funcionarios y funcionarias públicas que no cuenta con una identificación de defensores y defensoras de derechos humanos de pueblos indígenas ni con un conocimiento mínimo del derecho Internacional de los derechos humanos en cuanto a pueblos indígenas. Al respecto, mecanismos de protección internacional de derechos humanos, a nivel regional o universal, han observado y recomendado, una y otra vez, al Estado paraguayo a cambiar esta situación, sin embargo, la misma cuando cambia, lo hace para retroceder en el cometido de garantizar los derechos indígenas violando también, de esta manera, el principio internacional de los derechos humanos de progresividad y no regresividad.

Al respecto, el Comité CERD, al estudiar la situación del INDI, establece que la institución no cuenta con recursos suficientes para garantizar los derechos indígenas por lo que, entre sus observaciones al Estado paraguayo, manifiesta "que se asegure de que dicho instituto cuente con los recursos financieros,

6 INDI. Misión, https://www.paraguay.gov.py/indi, recuperado el 20 de julio de 2018. 
materiales, técnicos y humanos suficientes para el desempeño efectivo de sus funciones" (Comité CERD, 2016).

En el mismo tenor, el Comité CERD continúa explicando que

“...lamenta que el Estado parte no haya tomado las medidas necesarias... para fortalecer la autonomía institucional del INDI. Además, nota con preocupación que se ha reducido de manera significativa el presupuesto asignado a dicho instituto, lo cual limita su capacidad para llevar acabo su mandato de manera efectiva (art. 2, párr. 1)" (Comité CERD, 2016).

En este marco, Victoria Tauli-Corpuz también agrega que "El INDI, con su actual presupuesto y medios técnicos y humanos, difícilmente puede hacer frente a sus responsabilidades en relación con los derechos de los pueblos indígenas a las tierras, territorios y recursos naturales" (Tauli-Corpuz, 2016).

En este sentido, Tauli-Corpuz continúa diciendo que

La situación de marginación socioeconómica es también, en parte, resultado del racismo y la discriminación, que se reflejan igualmente en las medidas adoptadas para combatirla. En varios de los programas desarrollados por las instituciones gubernamentales, incluido el trabajo del INDI, la Relatora Especial pudo observar un enfoque paternalista que trata a las personas y pueblos indígenas como receptores indefensos o pupilos del Estado y no como titulares de derechos que deben ser respetados, protegidos y aplicados (Tauli-Corpuz, 2016).

En el contexto legislativo, a pesar de mandatos bien claros, a través de las tres sentencias de la Corte IDH contra el Estado paraguayo en los casos indígenas, el Estado paraguayo ha hecho caso omiso en relación con la obligación de reformar la Ley 904/81 "Del estatuto de las comunidades indígenas", legislación que se encuentra desfasada en varios aspectos y en disonancia con la Constitución así como desactualizada en relación a los principios y derechos que contiene el derecho Internacional de los derechos humanos. Así también esta ley, en cuanto a reivindicación territorial, es discriminatoria ya que deja en manos de los propietarios privados de las tierras, la decisión de devolverlas o no, aunque se hayan comprobado todos y cada una de las aristas en cuanto a comprobación de la territorialidad ancestral y el reclamo comunitario o de Pueblo

\section{DERECHO GLOBAL. ESTUDIOS SOBRE DERECHO Y JUSTICIA}


Indígena. No obstante, si bien es cierto que la Carta Magna establece la figura de la expropiación, ésta no se aplica casi nunca debido a la fuerte dominación, legal o ilegal, de los terratenientes y latifundistas en los tres poderes del Estado.

Esta situación no solo se puede observar en el INDI ya que la discriminación estructural se enquista en todos y cada una de las instituciones del Estado paraguayo, las que no cuentan con un enfoque intercultural, entre ellas, la Secretaría del Ambiente (SEAM), en adelante, SEAM, que tiene una visión discriminatoria en relación al otorgamiento de licencias ambientales, inclusive a través de procesos de corrupción. Éstas licencias y otras decisiones, institucionalizadas o no, benefician a actores del agronegocio en detrimento de los derechos territoriales y ambientales de los pueblos indígenas. Al respecto, TaulizCorpuz manifiesta que "...testimonios se refirieron particularmente a licencias ambientales otorgadas por la SEAM que incumplen la legislación interna y los estándares internacionales sobre los derechos de los pueblos indígenas" (TauliCorpuz, 2016).

En relación a derechos sociales y si se habla del derecho humano a la salud, al Comité CERD “...le preocupa la deficiente infraestructura, el desabastecimiento de medicamentos, la calidad y disponibilidad de los servicios de atención de la salud en las zonas rurales y remotas donde habitan principalmente los pueblos indígenas" (Comité CERD, 2016).

En el mismo marco de derechos, si se habla de la educación, se tiene que el mismo Comité exalta las diferencias significativas de acceso a la educación que afectan principalmente a los niños y niñas indígenas y afroparaguayos. Le preocupa al Comité, además, las altas tasas de analfabetismo entre la población indígena y afroparaguaya (Comité CERD, 2016).

Continuando con la limitada infraestructura del Estado paraguayo para hacer frente a los derechos humanos de los Pueblos Indígenas, la Corte IDH, en el caso de la comunidad Xákmok Kásek, explica que el caso de esta comunidad no es aislado y que en el Paraguay la discriminación contra los Pueblos Indígenas en Paraguay se da de hecho. En ese sentido la misma dice: 
En el presente caso está establecido que la situación de extrema y especial vulnerabilidad de los miembros de la comunidad se debe, inter alia, a la falta de recursos adecuados y efectivos que en los hechos proteja los derechos de los indígenas y no sólo de manera formal; la débil presencia de instituciones estatales obligadas a prestar servicios y bienes a los miembros de la Comunidad, en especial, alimentación, agua, salud y educación; y a la prevalencia de una visión de la propiedad que otorga mayor protección a los propietarios privados por sobre los reclamos territoriales indígenas, desconociéndose, con ello, su identidad cultural y amenazando su subsistencia física (Xákmok Kásek Vs. Paraguay, Corte IDH., 2010).

Es importante agregar, así como se ha observado, que esta situación de sistemática discriminación estructural, vulnera todos y cada uno de los derechos ambientales, civiles, culturales, económicos, políticos y sociales en el contexto de la interdependencia de los derechos humanos, lo que generan índices alarmantes de exclusión social, así como pobreza y extrema pobreza material.

En el caso Xákmok Kásek está establecido también que la situación de extrema y especial vulnerabilidad de los miembros de la comunidad se debe, inter alia, a la falta de recursos adecuados y efectivos que en los hechos proteja los derechos de los indígenas y no sólo de manera formal; la débil presencia de instituciones estatales obligadas a prestar servicios y bienes a los miembros de la comunidad, en especial, alimentación, agua, salud y educación; y a la prevalencia de una visión de la propiedad que otorga mayor protección a los propietarios privados por sobre los reclamos territoriales indígenas, desconociéndose, con ello, su identidad cultural y amenazando su subsistencia física.

Asimismo, quedó demostrado el hecho de que la declaratoria de reserva natural privada sobre parte del territorio reclamado por la Comunidad no tomó en cuenta su reclamo territorial ni tampoco fue consultada sobre dicha declaratoria (Xákmok Kásek Vs. Paraguay, 2010). 


\section{Consecuencias de la discriminación estructural}

En este último apartado, se expondrá las consecuencias de la discriminación estructural hacia los Pueblos Indígenas que consiste en una alarmante brecha de desigualdad en el acceso a derechos humanos, en la que la población indígena cuenta con índices negativos, desproporcionalmente más altos, que la población indígena.

Como ya se observó en el apartado histórico, la pobreza en Paraguay, en el último año, ha aumentado del $26.58 \%$ a $28.86 \%$, lo que significa al menos 1.950.000 paraguayos empobrecidos, a decir de la DGEEC. Esta institución oficial del Estado paraguayo también explica que, en relación con la extrema pobreza, ésta se ha aumentado, de un 5.42\% al 5,73\% y dentro de ésta la pobreza rural - en donde vive la mayor parte de la población indígena - ascendió a 39,72\% (DGEEC, 2017).

En ese contexto, la relatora Tauli-Corpuz, analiza la situación de exclusión social, pobreza y extrema pobreza de los pueblos indígenas en Paraguay, justamente desde la discriminación estructural y los derechos humanos. De esta manera, la misma manifiesta que "...los datos disponibles señalan que las tasas de pobreza y extrema pobreza entre los pueblos indígenas serían del $75 \%$ y el $60 \%$ respectivamente, mucho mayores que la media nacional" (Tauli-Corpuz, 2016).

La Relatora continúa diciendo que

Entre los indígenas menores de 5 años, el índice de pobreza extrema es del $63 \%$ (frente al $26 \%$ de media nacional) y el de desnutrición crónica, del 41,7\% (frente al 17,5\%). La falta de seguridad alimentaria y de acceso a agua potable (especialmente en el Chaco) fue mencionada por los representantes indígenas como problemas graves y recurrentes (Tauli-Corpuz, 2016).

Por último, ante este panorama de discriminación estructural y de desidia por parte del Estado paraguayo hacia los pueblos indígenas no queda otra salida que, por un lado, continuar con la defensa de los derechos humanos de estos pueblos y el activismo y por otro, y con más fuerza, la consolidación y el avance 
de las organizaciones y el movimiento indígena en Paraguay a los efectos de incidir más decididamente en el cumplimiento y la vigencia de sus derechos humanos.

\section{Conclusión}

Como se ha observado, delimitar el concepto y el contenido del principio de Igualdad y No Discriminación, tanto a nivel constitucional como a través del derecho internacional de los derechos humanos, ofrece elementos muy importantes a los efectos de profundizar en el análisis de la discriminación racial y la discriminación estructural contra los Pueblos Indígenas.

Es desde ahí que se fue avanzando desde algunas bases históricas que cimentaron la discriminación estructural principalmente a través del despojo territorial, directa o indirectamente, a través del Estado paraguayo, que viene consolidando hace siglos, privilegios históricos y estructurados en relación al modelo de agronegocio y agroexportador, situación que viola derechos humanos de estos pueblos.

Asimismo, se pudo corroborar en ese contexto, la visión mercantilista, latifundista y de deforestación irracional que propone y se asienta en la mirada del agronegocio la que, a través de una fuerte posición del Estado paraguayo, estructura la infraestrura económica en detrimento de los derechos territoriales de los pueblos indígenas.

Así las cosas, se ha observado como la limitada infraestructura, recursos humanos, inversión y presupuesto hacia el cumplimiento de los derechos humanos de los Pueblos Indígenas profundiza, de manera directa, esta discriminación estructural lo que agrava la situación material de estos pueblos hacia niveles exorbitantes de exclusión social, pobreza y extrema pobreza que se visibiliza, abiertamente, a través de la profunda diferencia en relación a la brecha en el acceso a derechos humanos si se compara la población no indígena y la población indígena, contando esta última con índices bajísimos de inclusión social. 
Por último, esta situación, inclusive, trasciende lo interno ya que el Estado paraguayo cuenta con tres sentencias condenatorias de la Corte Interamericana de Derechos Humanos por la violación directa de derechos territoriales y otros derechos económicos, sociales y culturales de comunidades indígenas en las que se obliga también, al Estado a empezar a delimitar acciones a los efectos de transformar sus prácticas discriminatorias.

Sin embargo, se observa un Estado que demuestra desidia e ineficacia en cumplir con las sentencias y las recomendaciones internacionales, situación que nos depara un panorama muy difícil en el cumplimiento de los derechos por lo que queda seguir en la permanente defensa de derechos humanos de pueblos indígenas $\mathrm{y}$, sobre todo, pensar, avanzar y consolidar las organizaciones y el movimiento indígena, sus estrategias y formas reivindicativas, respetando la autonomía y autodeterminación de estos pueblos.

\section{Bibliografía}

Comité para la Eliminación de la Discriminación Racial. Observaciones finales sobre los informes periódicos cuarto a sexto del Paraguay, 2018.

Corte IDH, El derecho a la información sobre la asistencia consular en el marco de las garantías del debido proceso legal, opinión consultiva del 30 de octubre de 1999, OC-16/99, párr. 114; Corte IDH, Caso Artavia Murillo y otros (fertilización in vitro) Vs. Costa Rica, (sentencia de 28 de noviembre de 2012, párr. 245)

Corte IDH, González y otras Vs. México, 2009.

Corte IDH, Sawhoyamaxa Vs. Paraguay, 2006.

Corte IDH, Xákmok Kásek Vs. Paraguay, 2010.

Corte IDH, Yakye Axa Vs. Paraguay, 2005.

Derecho y Grupos desaventajados, Gargarella, R., Editorial Gedisa,

Universidad de Palermo y Yale Law School, Barcelona, 1999.

Diccionario Real de la Academia Española

Dirección General de Estadística, Encuestas y Censos, Paraguay. 
From Individual to Structural Discrimination, Fred L. Pincus en Fred L. Pincus y Howard J. Ehrlich (eds.), Race and Ethinic Conflict, Contending Views on Prejudice, Discrimination and Ethnoviolence, Boulder, Westview Press, 1994.

Galeano, E. (2010) Las venas abiertas de América Latina. Buenos Aires: Editorial Siglo Veintiuno.

Naciones Unidas (2015) Informe de la relatora especial sobre los derechos de los pueblos indígenas, Victoria Tauli-Corpuz, Situación de los pueblos indígenas en el Paraguay, Consejo de Derechos Humanos, $30^{\circ}$ período de sesiones. Tema 3 de la agenda, 13 de julio de 2015

Naciones Unidas (2017) Informe de la relatora especial sobre formas contemporáneas de esclavitud, Urmila Bhoola, incluyendo sus causas y consecuencias, al concluir su visita al Paraguay del 17 al 24 de julio del 2017.

Naciones Unidas. (2016) Observaciones finales sobre los informes periódicos cuarto a sexto del Paraguay del Comité para la Eliminación de la Discriminación Racial.

Navarrete, R. (2010) Gobernalidad Neoliberal y Movimientos Indígenas en América Latina. Revista de la Universidad Bolivariana, Volumen 9, N²7, pág. 8.

Pelletier, P. (2014) La discriminación estructural en la evolución jurisprudencial de la Corte Interamericana de Derechos Humanos. Revista IIDH, Vol. 60.

Zanardini, J. (2010) Los Pueblos Indígenas del Paraguay. Asunción: El Lector.

Cómo citar este artículo: Mendieta, M. (2018). El principio de igualdad y no discriminación. Aproximaciones a la discriminación estructural del Estado paraguayo hacia los pueblos indígenas. Derecho Global. Estudios sobre Derecho y Justicia, 4 (10), pp. 153-180. 